\title{
Computational pharmaceutical materials science
}

\author{
Jacco van de Streek \\ From 9th German Conference on Chemoinformatics \\ Fulda, Germany. 10-12 November 2013
}

Pharmaceutical materials science addresses the physical solid-state properties of pharmaceutical products, such as solubility and stability of crystal structures. Especially the different properties of different polymorphs, salts and hydrates of an Active Pharmaceutical Ingredient (API) are of interest, although more recently the amorphous state has also received considerable attention.

Calculations, such as dispersion-corrected Density Functional Theory [1] (DFT-D), can help to determine crystal structures from challenging experimental data (e.g., structure determination from X-ray powder diffraction data [2]) and can help to identify the most stable form of an API (crystal structure prediction [3]). Molecular Dynamics (MD) can be used to resolve disorder and phase transitions in crystal structures, and more recently MD is being used to investigate the amorphous state.

This presentation will give several examples of the projects that are currently underway in our group.

Published: 11 March 2014

\section{References}

1. Neumann MA, Perrin M-A: Energy Ranking of Molecular Crystals Using Density Functional Theory Calculations and an Empirical van der Waals Correction. J Phys Chem B 2005, 109:15531-15541.

2. Naelapää K, Van de Streek J, Rantanen J, Bond AD: Complementing HighThroughput X-ray Powder Diffraction Data with Quantum-Chemical Calculations: Application to Piroxicam Form III. J Pharm Sci 2012, 101:4214-4219.

3. Kendrick J, Leusen FJJ, Neumann MA, Van de Streek J: Progress in Crystal Structure Prediction. Chem Eur J 2011, 17:10736-10744.

doi:10.1186/1758-2946-6-S1-O21

Cite this article as: van de Streek: Computational pharmaceutical materials science. Journal of Cheminformatics 2014 6(Suppl 1):021.

Correspondence: jacco.vandestreek@sund.ku.dk

Department of Pharmacy, University of Copenhagen, Copenhagen, 2100, Denmark

(0) 2014 van de Streek; licensee Chemistry Central Ltd. This is an Open Access article distributed under the terms of the Creative Commons Attribution License (http://creativecommons.org/licenses/by/2.0), which permits unrestricted use, distribution, and 